\title{
EXPERIÊNCIAS EDUCACIONAIS NO SÉCULO XVI: A FORMAÇÃO DA CASA DE MENINOS DE SÃO PAULO DE PIRATININGA
}

Felipe Ziotti Narita ${ }^{1}$

\section{RESUMO}

Este estudo pretende analisar as atividades educacionais jesuíticas desenvolvidas na Casa de Meninos de São Paulo de Piratininga, localizada no interior da capitania de São Vicente, entre 1554 e 1556: período que contou com a participação direta do jesuíta Manuel da Nóbrega e que compreende as primeiras experiências pedagógicas vivenciadas na constituição daquele núcleo de ensino. Para tanto, a pesquisa voltou-se à análise de cartas escritas por jesuítas, durante o recorte temporal proposto, que relatam as atividades educacionais ministradas inicialmente e as condições sob as quais se desenvolveram a educação e a formação religiosa dos indígenas na Casa de Meninos de São Paulo de Piratininga. Com o cultivo de um modelo pedagógico indissociável da formação educacional na religião, os jesuítas estruturaram uma cultura escolar que encontrou respaldo nos métodos catequéticos da Companhia. Assim, embora afetado pela precariedade material e pelos infortúnios, o sistema de ensino e de formação religiosa jesuítico da Casa de Meninos fomentou as bases para a fixação de um povoado em São Paulo de Piratininga.

Palavras-chave: Educação colonial, catequese, jesuítas.

\section{INTRODUÇÃO}

O período compreendido entre 1549 e 1759, do desembarque da primeira missão da Companhia de Jesus $^{2}$ no Brasil à expulsão da mesma por meio de um Alvará régio, foi marcado pela forte atuação dos jesuítas na organização do ensino na colônia. Durante os três séculos de ensino notadamente jesuítico ${ }^{3}$, estruturaram-se os pilares da educação colonial em

\footnotetext{
${ }^{1}$ Graduando do curso de História da Faculdade de História, Direito e Serviço Social - UNESP - Campus de Franca. Pesquisa desenvolvida sob orientação da Prof ${ }^{\mathrm{a}}$.dr ${ }^{\mathrm{a}}$. Vânia de Fátima Martino. Membro do grupo de pesquisa do $\mathrm{CNPq}$ intitulado "Políticas públicas e democratização do ensino no Brasil: a implementação das propostas educacionais: mudanças e permanências”. E-mail: narita@netsite.com.br.

${ }^{2}$ Considerada uma das mais importantes ordens religiosas do século XVI, a Companhia de Jesus teve origem em 1534, com a reunião de estudantes - dentre eles, Inácio de Loyola. A Companhia foi oficializada por Roma por meio da bula Regimini Militantis Ecclesiae, em 1540.

${ }^{3}$ Malgrado a proeminência jesuítica nas atividades de ensino, conforme afirma Rubens Borba de Moraes (2006, p. 15), "seria cometer grave exagero pensar que o ensino era ministrado, nos primeiros séculos, unicamente pelos jesuítas, e que só eles possuíam boas bibliotecas. As outras ordens religiosas, principalmente as dos beneditinos, franciscanos e carmelitas, tinham escolas anexas aos seus conventos e exerciam papel importante na instrução do povo, principalmente, no ensino das primeiras letras".
} 
torno dos quais se organizou significativa parcela da sociedade brasileira ${ }^{4}$. Nesse sentido, na análise dos métodos pedagógicos desenvolvidos nos núcleos de catequese jesuíticos implica sublinhar o desenvolvimento de uma cultura escolar que, sobretudo, evidenciava os contrastes culturais entre europeus e indígenas, de modo que se situa no bojo da formação da Educação no Brasil.

A ação jesuítica desenvolvida no Brasil do século XVI processou-se a duras penas. Embrenhar-se em meio às matas, modelar-se em conformidade com as condições climáticas e contornar a geografia do trópico deviam ser etapas superadas em nome da ação missionária em prol dos verdadeiros ofícios de fé que visavam a conduzir os preceitos de uma vida cristã ao gentio. Localizada nas regiões mais interioranas da Capitania de São Vicente, a Casa de Meninos de São Paulo de Piratininga, local destinado à educação dos nativos, produto de um longo projeto jesuítico liderado por Manuel da Nóbrega $^{5}$, localizava-se na fronteira com o sertão, terra pouco conhecida que acobertava monstros e prodígios (TAUNAY, 1920).

Dessa forma, em meio a um ambiente que escancarava suas hostilidades, os jesuítas organizaram um núcleo de formação. Os contornos geográficos eram adversos: com uma topografia acidentada, coberta por uma densa mata,

[...] na altura de São Vicente, a Serra do Mar revestida pela exuberante mata tropical atlântica, o branco deparou com uma região de vastos campos cobertos de vegetação rasteira, com pequenas árvores, esparsas ou agrupadas e alguns capões de mato. Eram os campos de Piratininga, já conhecidos pelo índio. Ali se estendia a planície aluvial formada pelo Tietê, Pinheiros e Tamanduateí e pelos ribeirões seus afluentes (HOLANDA, 1985, p. 273).

\section{Descrição do trabalho desenvolvido e resultados obtidos}

A região de Piratininga já aparecia nas cartas jesuíticas antes da definitiva fixação de um núcleo de catequese organizado por Nóbrega. Assim, em uma carta escrita em São Vicente, datada de novembro de 1550, o padre Leonardo Nunes escreveu:

\footnotetext{
${ }^{4}$ Segundo Fernando de Azevedo (1963, p. 539), "em 1759, com a expulsão dos jesuítas, o que sofreu o Brasil não foi uma reforma no ensino, mas a destruição pura e simples de todo o sistema colonial de ensino jesuítico. Não foi um sistema ou tipo pedagógico que se transformou ou se substituiu por outro, mas uma organização escolar que se extinguiu sem que essa destruição fosse acompanhada de medidas imediatas e bastante eficazes para lhe atenuar os efeitos e reduzir sua extensão".

${ }^{5}$ Chefe da primeira missão jesuítica na América, Nóbrega desembarcou na Bahia, em 1549, juntamente com a armada do governador-geral Tomé de Sousa. Foi um dos jesuítas de maior destaque nas missões do Brasil do século XVI.
} 
Aquí me dixeron que em el Campo quatorze o quinze leguas daquí, entre los Indios estava alguna gente christiana derramada, y passávase el año sem oyr missa y sin se confessar, y andavan en una vida de selvajes [...] Pusiéronlo luego por obra y tomaron luego campo para la iglesia. Gasté dos o tres dias com ellos, y confessé algunos y diles el Sanctissimo Sacramento (LEITE, 1952a, p. 207-208)

A aedificatio ecclesiae descrita por Leonardo Nunes ilustra a proposta jesuítica de conduzir a fé aos nativos do sertão. Com a fé católica e a edificação de uma igreja, ainda que provisória, os jesuítas cultivaram dois elementos indissociáveis dos verdadeiros e mais puros valores da civilização. A fim de fixá-los nos modos de vida dos indígenas, a formação de uma Casa de Meninos direcionada à catequese selou esse movimento, de modo a mesclar as práticas sociais cristãs em um sistema de ensino que ocupou proeminência no Brasil colonial.

Com a oficialização concretizada no dia 25 de janeiro de 1554, uma carta escrita por José de Anchieta ${ }^{6}$ em setembro de 1554, em Piratininga, relata a cerimônia: "no ano do Senhor de 1554, chegámos a ela a 25 de janeiro e celebrámos missa numa casa pobrezinha e muito pequena no dia da Conversão de S. Paulo" (LEITE, 1952b, p. 105). Após o estabelecimento da Casa de Meninos, na mesma carta, o então jovem Anchieta informa acerca da transferência dos meninos, organizada por Nóbrega, do Colégio de São Vicente para Piratininga:

Como era muito trabalhoso e difícil, por causa da grande aspereza do caminho, ao nosso Padre pareceu melhor no Senhor mudarmo-nos para esta povoação de Índios, que se chama Piratininga. Isto por muitas razões: primeiro, por causa dos mantimentos [...] e especialmente porque se abriu por aqui a entrada para inúmeras nações, sujeitas ao jugo da razão (LEITE, 1952b, p. 105)

Anchieta (LEITE, 1952b, p. 106) ainda diz respeito acerca da presença de oito membros da Companhia na Casa de Meninos, mas, conforma sublinha Serafim Leite (1965, p. 21), a imprecisão da documentação acerca do número de missionários presentes na Casa sempre deixa margem para incertezas. Com efeito, Anchieta prossegue seu escrito no sentido de apresentar mais alguns detalhes sobre as atividades da Casa de Meninos. Nesse sentido, uma vez que "o principal alimento desta terra é farinha de pau, que se faz de certas raízes que se plantam, e chamam mandioca" (LEITE, 1952b, p. 112), a Casa dos jesuítas em Piratininga, gradativamente, imprimia um novo ritmo social que gravitava em torno das atividades

\footnotetext{
${ }^{6}$ Chegou ao Brasil com a armada de D. Duarte da Costa, em 1553. Anchieta foi designado para trabalhar com Manuel da Nóbrega, de forma que obteve papel de destaque na administração jesuítica no Brasil.
} 
voltadas à formação educacional dos nativos. Assim, conforme expõe Anchieta (LEITE, 1952b, p. 106),

$\mathrm{Na}$ Escola, muito bem ensinados pelo Mestre António Rodrigues, encontram-se 15 já baptizados e outros, em maior número, ainda catecúmenos. Os quais, depois de rezarem de manhã as ladainhas em coro na Igreja, a seguir à lição, e de cantaram à tarde a Salve Rainha, são mandados para suas casas; e todas as sextas-feiras fazem procissões com grande devoção, disciplinando-se até o sangue.

A instalação da Casa de Meninos, a paupercula domus jesuítica, convivia sob a penúria dos primeiros tempos: precariedade e hostilidades da terra, estes foram os motes sobre os quais se assentou a formação educacional jesuítica em Piratininga. Affonso Taunay (1921, p. 21), nesse sentido, afirma: "desconfortável, em extremos, a humílima choça, mas para aquelles homens, absortos no proseguimento do mais elevado ideal, significava o primeiro marco da conquista espiritual de milhares de almas, que então se iniciava". Para a árdua tarefa de conversão do gentio, a obra jesuítica na Casa de Meninos comportava um viés catequético bastante profundo, no sentido de

[...] ensinar os meninos índios para com eles atrair os pais; ensinar os moços portugueses e da terra para futuros evangelizadores, e, se fosse possível, como religiosos da Companhia de Jesus, esperança que a princípio alimentou acerca dos filhos dos índios ou pelo menos dos filhos das índias (LEITE, 1965, p. 38).

Sobre as atividades educacionais ministradas na Casa de Meninos nos primeiros momentos, José de Anchieta escreveu importantes relatos, já que, na condição de Magister Gramaticae, ministrava aulas de aperfeiçoamento da gramática latina aos membros da Companhia, bem como auxiliava nos serviços necessários à manutenção da Casa. Nesse sentido, em uma outra carta de setembro de 1554, escrita em Piratininga, ele escreve sobre o trabalho missionário dos jesuítas na formação educacional dos meninos índios:

Por lo qual nuestro pincipal fundamento es en la doctrina de los niños, los quales les enseño a leher, escrivir y cantar; éstos trabajamos de tener debaxo nuestra mano para que después vengan a succeder em lugar de sus padres y hagan pueblo de Dios (LEITE, 1952b, p. 121).

Referida na mesma carta como schola puerorum, a Casa de Meninos de São Paulo de Piratininga, fincada em meio ao hostil e misterioso sertão, estruturava um espaço para a 
educação que tomava como eixo o desenvolvimento da catequese sobre aquela "gente tan indómita y bestial, que toda su felicidad tiene puesta em matar y comer carne humana" (LEITE, 1952b, p. 120). Com efeito, o desafio ao espírito virtuoso da ação missionária, imersa em uma terra onde perduravam os sinais da barbárie, era construir novas formas de práticas sociais que perpassavam a educação do gentio nos moldes cristãos. Nesse sentido, o Irmão Pero Correia, em uma carta datada de julho de 1554, escrita em São Vicente, ao escrever sobre a schola legendi, scribendi et cantandi, a Casa de ler, de escrever e de cantar dos Meninos de São Paulo de Piratininga, relata algumas atividades educacionais desenvolvidas: "em el mísmo lugar ay escuela de niños y um Hermano tiene cuydado de enseñarlos a ler y a escrevir, y a algunos dellos a cantar" (LEITE, 1952b, p. 70).

Com a proposta educacional jesuítica pautada na catequese, novas formas de representação da vida social começaram a ser construídas. Atrair o gentio para a educação nos valores cristãos tornou-se um dos grandes dilemas da educação missionária jesuítica no Brasil. Dessa forma, os jesuítas desenvolviam "atividades centradas na música, na dança, na 'teatralidade' da vida tribal repleta de rituais, movimentos, cores e sons" (FERREIRA JÚNIOR; BITTAR, 2004). Eram formas de representar uma organização social cujo grande fator de coesão e de ordenamento era a religiosidade, que encontrava correspondência nos signos católicos. Assim, Pero Correia (LEITE, 1952b, p. 67) prossegue com seu testemunho ao indicar

[...] que quando entravan em algún lugar huno de los niños llevava uma cruz pequeña alevantada, y ivan cantando las letanías por una cierta manera muy buena; y luego los niños de los lugares se ayuntavan com ellos, y toda la gente se maravillava mucho de cosa tan nueva. Recebíanlos por donde yvan muy bien; y quando se partían de los lugares también salían cantando lãs letanías, y algunos de los niños dexavan a sus padres y madres y ívanse com ellos.

Como atividade central do ensino da Casa de Meninos, a catequese dos meninos tupi compreendia estudos direcionados à leitura, à escrita e ao canto, o que evidencia que o responsável pelas lições detinha alguma familiaridade com a terra. Assim, conforme expõe Serafim Leite (1965, p. 154), era necessário um mestre que falasse não só o português para ensinar, mas também que detivesse certo conhecimento do tupi, instrumento necessário para a comunicação com os alunos. Para essa tarefa, nos primeiros anos, foi designado Antônio 
Rodrigues $^{7}$, que permaneceu na Casa até 1556. Os resultados decorrentes do ensino catequético já aparecem em uma carta escrita em São Vicente, em março de 1555, por José de Anchieta: “estes nossos catecúmenos, de que nos ocupamos, parecem apartar-se um pouco dos seus antigos costumes, e já raras vezes se ouvem os gritos desentoados que costumam fazer nas bebedeiras" (LEITE, 1952b, p. 194). Também o sacramento do matrimônio católico, tão violado no cotidiano colonial, começava a se definir em Piratininga:

"Donde se segue que frequentam mais a Igreja, sofrem com mais paciência repreensões e censuras, e alguns deles, casados em legítimo matrimônio, pedem-nos com grande empenho que lhes ensinemos o modo de viver bem" (LEITE, 1952b, p. 194).

Um novo modo de vida começava a tomar corpo. Embora ainda paupérrima e completamente entregue às oscilações da fortuna, a Casa de Meninos, lentamente, constituía uma nova dinâmica social na região. Esses lentos sinais de mudança eram efeitos decorrentes, sobretudo, do ensino. Regidos pelos rudimentos da catequese ministrada na Casa, os cathecumeni, de que fala Anchieta, começavam a se formar nas práticas cristãs:

O ensino dos meninos aumenta dia a dia e é o que mais nos consola; os quais vêm com gosto à Escola, sofrem os açoites e têm emulação entre si. Destas coisas escrevi por miúdo na carta precedente (LEITE, 1952b, p. 194).

Pouco antes de partir rumo à Bahia, em maio de 1556, em São Vicente, Manuel da Nóbrega escreveu uma carta destinada a Lisboa em que ele apresenta um relato geral sobre a situação da Casa de Meninos. Com o cultivo das atividades centradas na escrita, no canto e na leitura - os três fundamentos da educação catequética da Casa de Meninos de São Paulo de Piratininga -, na carta, Nóbrega relata a transferência dos meninos índios para uma povoação interiorana, nos campos de Piratininga, onde foi erguida a Casa:

[...] e na terra aver poucas esmolas para tanta gente, foi-me forçado, des que a esta Capitania vim, a passar os meninos a huma povoação de seus pais, donde erão a maior parte delles, e com elles passei alguns Irmãos e fizemos casa e igreja, e tivemos conosco somente alguns que erão de outras partes (LEITE, 1952b, p. 281).

\footnotetext{
${ }^{7}$ Participou da fundação de Buenos Aires, em 1546. Anos mais tarde, ao ingressar na Companhia de Jesus, colaborou com Nóbrega no agrupamento de índios no sertão de São Vicente, que deu origem à Aldeia de Piratininga (LEITE, 1965).
} 
Em um tom de queixa, Nóbrega informa acerca da precariedade material da Casa de Meninos, de modo a evidenciar que uma dinâmica social bastante peculiar começava a se articular ao redor do núcleo de catequese. Se as condições materiais eram precárias, a Casa de Meninos estava comprometida, sobretudo, em função do descaso da Coroa e dos próprios quadros eclesiásticos da colônia. Assim, Nóbrega (LEITE, 1952b, p. 283) afirma que

Vemos que, pêra se fazer aquella casa de São Paulo collegio, não tem mais que a grangearia daquelles homens com aqueles escravos, os quais morerão e nós não buscamos outros; assi mesmo o Irmão ferreiro hé doente e velho, não sei quanto durará; as vaquas forão aquiridas pera os meninos da terra $\mathrm{e}$ são suas; há esmola d'El-Rei he incerta.

As alternativas de Nóbrega para a resolução das precariedades que comprometiam o triunfo da educação jesuítica deixavam a esfera das propostas de ensino para passarem ao âmbito burocrático. Nesse sentido, conforme expõe Nóbrega (LEITE, 1952b, p. 283), “pera não ser collegio, senão casa que viva de esmolas, hé impossivel poderem-se sustentar os Irmãos daquella casa". Com um quadro de mestres ampliado e com um espaço físico de maiores dimensões e mais bem estruturado, Serafim Leite (1938, p. 297) observa que os Colégios da Companhia eram entidades jurídicas e morais capazes de possuir bens, ao compasso que as Casas de Meninos eram unidades menores em que os padres administravam bens alheios.

No final da carta, Nóbrega escreve sobre as condições favoráveis, desenvolvidas em torno da Casa de Meninos, que seriam seladas com a fixação de um Colégio. Assim, a escolha do local propício para o desenvolvimento de um núcleo de formação educacional jesuítico em pleno sertão de São Vicente só devia ser lembrada porque a mesma encontrou respaldo em construções missionárias que edificavam grandes símbolos cristãos em meio aos bandos pagãos: a igreja e a Casa de Meninos. Compondo um exercício de memória cujo objetivo era resgatar o mote virtuoso da ação jesuítica, Nóbrega (LEITE, 1952b, p. 284) informa que

[...] com isto e com o mais que a casa tem seria collegio fixo, porque já tem casas e igreja e cerqua, em muito boom sitio posto, o milhor da terra, de toda abastança que na terra pode aver, em meo de muitas povoaçõis de Índios e perto da Villa de S. André, que he de christãos, e todos os christãos desejão hir aly viver se lhes dessem licença.

Em 1556, quando Nóbrega escreveu a citada carta, o embrião de uma povoação já começava a se desenvolver em São Paulo de Piratininga. Conforma observa Serafim Leite (1938, p. 279), durante o período, a igreja já comportava uma melhor estrutura, de tal forma 
que Luiz da Grã ${ }^{8}$, após a visita à crescente povoação, registrou seu otimismo em relação à Casa e ao progresso dos serviços espirituais na região. Com efeito, a Casa de Meninos de São Paulo de Piratininga constituiu-se como um núcleo fixador da povoação, de modo que começou a articular e a aquecer uma dinâmica social bastante peculiar ao seu redor, com novos ritmos de novas formas de organizar um espaço que, a partir daquele momento, tornava-se legitimamente cristão.

\title{
2. Considerações finais
}

Assim, com a fixação dos muros, com o desenvolvimento da educação jesuítica e com a expansão do povoado até a consolidação como Vila, em 1560, inúmeras adversidades tiveram que ser contornadas. Conforme a análise das cartas jesuíticas transparece, sucessos e insucessos, tudo permanecia tributário da construção de um sistema de formação educacional pautado na catequese que, a muito custo, fora desenvolvido e mantido pelos jesuítas que transitaram na Casa de Meninos de São Paulo de Piratininga. Com a construção de raízes que crivaram marcas na Educação brasileira, o sistema pedagógico dos jesuítas representa, sobretudo, um modelo educacional que se sustentou por muitos séculos na história da Educação no Brasil, com muito mais permanências que grandes rupturas.

\section{EDUCATIONAL ACTIVITIES ON 16St CENTURY: THE HOUSE OF BOYS IN SÃO PAULO DE PIRATININGA}

\begin{abstract}
This study intends to analyze the Jesuit educational activities developed at "Casa de Meninos de São Paulo de Piratininga", located inside the captaincy of "São Vicente", between 1554 and 1556: period in that there was the direct participation of the Jesuit Manuel da Nóbrega and that includes the first pedagogic experiences lived during the constitution of that teaching nucleus. For so much, the research emphasized the analysis of letters written by Jesuits during the proposed temporary cutting, that tell the education activities supplied initially and the conditions under which grew the education and the natives' religious formation at "Casa dos Meninos de São Paulo de Piratininga". With the cultivation of a pedagogic model associated to the education formation in the religion, the Jesuits structured a school culture that found support in the catechetical methods of the Company. Like this, although affected for the material precariousness and for the misfortunes, the education and religious formation system
\end{abstract}

\footnotetext{
${ }^{8}$ Padre Jesuíta que desembarcou no Brasil em 1553, juntamente com a armada que trazia D. Duarte da Costa, o segundo governador-geral do Brasil.
} 
of "Casa dos Meninos de São Paulo de Piratininga" fomented the bases for the fixation of a village in "São Paulo de Piratininga".

Keywords: Colonial education. Catechesis. Jesuits.

\section{REFERÊNCIAS BIBLIOGRÁFICAS}

AZEVEDO, F. de. A cultura brasileira: introdução ao estudo da cultura no Brasil. Brasília: Editora da UnB, 1963.

FERREIRA JUNIOR, A.; BITTAR, M. Pluralidade lingüística, escola de bê-á-bá e teatro jesuítico no Brasil do século XVI. Educ. Soc., Campinas, v. 25, n. 86, 2004. Disponível em: <http:/www.scielo.br/scielo.php?script=sci_arttext\&pid=S010173302004000100009\&ln $\mathrm{g}=\mathrm{en} \& \mathrm{nrm}=$ iso $>$. Acesso em: 18 jan. 2007.

HOLANDA, S. B. de. A época colonial: do descobrimento à expansão territorial. São Paulo: DIFEL, 1985.

LEITE, S. Cartas dos primeiros jesuítas do Brasil. São Paulo: Comissão do IV centenário da cidade de São Paulo, 1952a. v. 1.

. Cartas dos primeiros jesuítas do Brasil. São Paulo: Comissão do IV centenário da cidade de São Paulo, 1952b. v. 2.

História da Companhia de Jesus no Brasil - Tomo I (século XVI): o estabelecimento. Rio de Janeiro: Civilização Brasileira, 1938. 1965.

. Novas páginas de História do Brasil. São Paulo: Companhia Editora Nacional,

MORAES, R. B. de. Livros e bibliotecas no Brasil colonial. Brasília: Briquet de Lemos, 2006.

TAUNAY, A. de E. S. Paulo nos primeiros annos (1554-1601): ensaio de reconstituição social. [S.l: s.n], 1920.

São Paulo no século XVI: história da villa piratiningana. [S.1: s.n], 1921. 